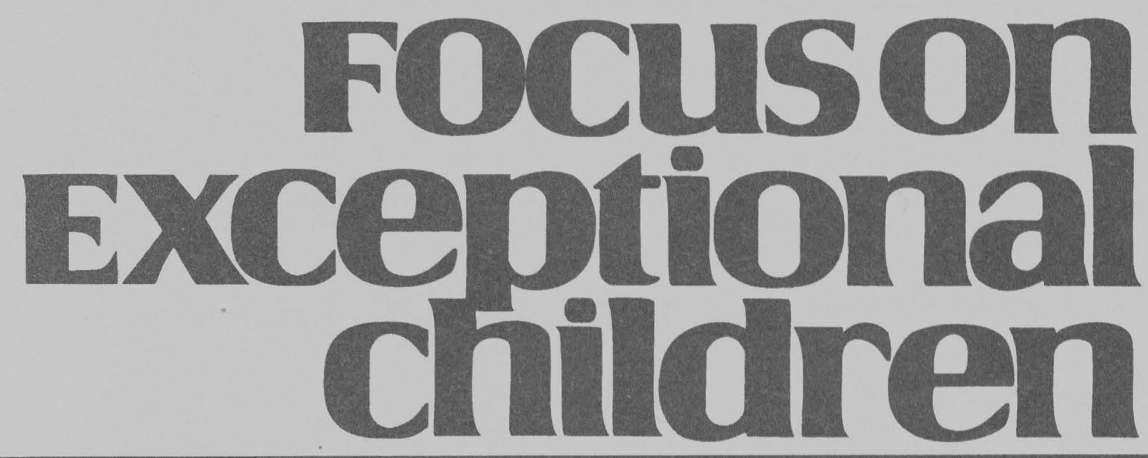

\title{
The Central Role of Teaching Social Skills
}

\author{
Beverley H. Johns, E. Paula Crowley, and Eleanor Guetzloe
}

Blaine was participating in a pizza party for students who had perfect attendance for the month. When he wanted another piece of pizza, he snapped his fingers at one of the teacher assistants. The assistant, who was very upset, later learned that at the dinner table Blaine's father snapped his fingers to get what he wanted from Blaine's mother. Obviously, finger-snapping for food was inappropriate and offensive behavior at school, but it was a behavior that Blaine had learned at home.

We can no longer assume that all children come to school knowing how to behave and how to respond appropriately in varying social situations. Some children believe that the only way to express anger is to hit someone or to yell until they get attention. Albert, a 15-year-old student who was involved in a gang, did not know how to wait his turn to speak and continually strove, like a 3- or 4-year-old, to get the teacher's attention. $\mathrm{He}$ became very upset if someone else in his instructional $\mathrm{E} / \mathrm{BD}$ class received attention. Tyler, a 16-year-old, is in a regular high school but is scorned by other students because he continually acts like a Power Ranger. Jenny, a 10-year-old receiving resource services from the special education teacher in the building, speaks very quietly and cannot assert herself to make her needs known. All of these students need to be taught appropriate social skills.

Mathur and Rutherford (1996) state that adequate social development can be considered the foundation of personal and social adjustment in life. Deficits in social skills are linked to poor social adjustment, mental health problems, delinquency, and low selfconcept. According to Deshler, Ellis, and Lenz (1996): "Social skills knowledge is just as important as content knowledge" (p. 371). They believe that poor social skills in school are related to the following factors: (1) limited opportunities to learn; (2) negative academic and social self-concept; and (3) social isolation.

According to Shores and Jack (1996), children and youth are identified as having behavioral disorders based on their excesses and their deficits of social behavior. They respond to available social stimuli in unpredictable ways.

\footnotetext{
Beverley H. Johns was a program supervisor for the Garrison Alternative School in Jacksonville, Illinois. She is now a prominent speaker and consultant to school districts throughout the United States. E. Paula Crowley is a professor in the Department of Special Education at Illinois State University. Eleanor Guetzloe is a professor emerita in education at the University of South Florida. This article was adapted from a chapter in their book entitled Effective Curriculum for Students With Emotional and Behavioral Disorders, published by Love Publishing Company.
} 
The teaching of social skills should be an integral part of any program for $\mathrm{E} / \mathrm{BD}$ students. We have observed $\mathrm{E} / \mathrm{BD}$ teachers who work on developing students' skills in reading, math, and writing, but fail to spend time in the direct teaching of social skills. But when we ask people in business and industry what skills they want workers to have, they consistently answer: "We want them to be able to get along with other people." Business and industry leaders can teach students job-specific skills but need workers who have appropriate social skills. If we are to prepare our students for the world of work, we must provide direct instruction in social skills.

Mathur and Rutherford (1996) define social skills as socially acceptable patterns of behaviors that allow students to gain social reinforcement and acceptance and avoid aversive social situations. "A socially skilled person is capable of managing his or her social environment by understanding and responding to social situations effectively" (p. 21). They believe that the purpose of training in social skills should not be restricted to teaching a specific social skill in one context but should be to promote overall social functioning that includes a wide repertoire of social skills that produce socially acceptable responses in various social situations. Further, they define social competence "as a composite or

\section{Focuson
Exceptional
children}

ISSN $0015-511 \mathrm{X}$ FOCUS ON EXCEPTIONAL CHILDREN (USPS 203-360) is published monthly except June, July, and August as a service to teachers, special educators, curriculum specialists, administrators, and those concerned with the special education of exceptional children. This publication is annotated and indexed by the ERIC Clearinghouse on Handicapped and Gifted Children for publication in the monthly Current Index to Journals in Education (CIJE) and the quarterly index, Exceptional Children Education Resources (ECER). The full text of Focus on Exceptional Children is also available in the electronic versions of the Education Index. It is also available in microfilm from Xerox University Microfilms, Ann Arbor, MI. Subscription rates: individual, \$36 per year; institutions, $\$ 48$ per year. Copyright (C) 2005, Love Publishing Company. All rights reserved. Reproduction in whole or part without written permission is prohibited. Printed in the United States of America. Periodical postage is paid at Denver, Colorado. POSTMASTER: Send address changes to:

Love Publishing Company

Executive and Editorial Office P.O. Box 22353

Denver, Colorado 80222

Telephone (303) 221-7333

Susan T. Warhover Editor
Stanley F. Love

Publisher multitude of generalized social skills that contribute to a person's overall social functioning, whereas social skills refer to situationally specific patterns of behaviors that are identifiable and definable. The ultimate purpose of teaching specific social skills is to promote the overall functioning or social competence of the individual.... Social skills are the basic ingredients of social competence" (p. 22).

Warger and Rutherford (1993) make the following distinctions between social skills and social competence. Social skills are specific, identifiable, discrete, learned behaviors that result in positive social consequences in social situations. Social skills are viewed as part of the broader construct known as social competence. "Social competence is an observer-based judgment about a person's social functioning, whereas social skills are specific behaviors that form the basis for socially competent behavior" ( $\mathrm{p}$. 21). Gresham (1998) believes that the degree to which children learn to establish, develop, and maintain satisfactory interpersonal relationships with their peers and adults is the essence of social competence.

Social skills programming has many facets. As teachers plan the teaching of social skills to students, they must ask these questions (outlined by Mathur and Rutherford, 1996):

What are the social skills deficits?

What are the reasons for the deficits? Does the student have adequate knowledge of the skill?

Does the student have enough opportunity to use the target skills?

Are reinforcement contingencies effectively arranged to promote the response? (p. 23)

They suggest that "targeting the peer group rather than the student for social skills training, and altering the classroom environment to facilitate positive peer networks and to discourage negative peer influences are examples of strategies that need to be examined in future social skills research" (p. 23).

In summarizing, Mathur and Rutherford (1996) state that the success of social skills training depends on several factors, including the following:

1. Social validity of target skills

2. A sound conceptual basis for social skill deficits

3. Precision and comprehensiveness in assessment procedures

4. Clarity in description of social skills interventions

5. Attention to contextual factors

6. Systematic programming for generalization (p. 26)

Walker, Colvin, and Ramsey (1995) believe that the two major indications of the success or failure of any social skills training effort are as follows: 
1. Whether the student targeted acquires and demonstrates unlearned social skills or uses already acquired skills in a more competent manner, and

2. Whether the process of acquiring the skill leads to improved social effectiveness and acceptance by key social agents in the student's world (p. 235).

Quinn, Kavale, Mathur, Rutherford, and Forness (1999) conducted a meta-analysis of 35 studies investigating the effects of social skill interventions for students with emotional and behavioral disorders. The results showed that the use of universal social skill interventions-those that are given to whole groups of students with emotional and behavioral disorders-has produced less than substantial changes in behavior. These researchers determined that group interventions are not as effective; rather what students with $\mathrm{E} / \mathrm{BD}$ need is an increase in specially designed individualized instruction. They also argue that the cost of not teaching social skills is extremely high.

Gresham (1998) summarizes social skills training research that shows a weak effect, particularly for students with emotional and behavioral disorders. However, he believes that the poor outcomes can be attributed in part to these factors in the research: use of socially invalid and insensitive outcome measures; failure to match social skills interventions to specific social skills deficits; and failure to program for functional generalization. He advises that social skills training not be utilized as a stand-alone intervention but as an integral part of the curriculum.

In this article we will discuss the critical components of social skills training, utilizing a multifaceted approach. Those components include the following:

1. Direct instruction.

2. The teachable moment.

3. The teacher as a role model for appropriate social skills.

4. Recognition of appropriate social skills throughout the day.

5. Special group projects.

6. Conflict resolution.

7. Teaching self-management, including social skills strategies and anger management.

This article will also discuss the selection of social skills materials for the classroom.

\section{DIRECT INSTRUCTION OF SOCIAL SKILLS}

Rutherford, Quinn, and Mathur (1996) point to research that validates the effectiveness of social skills training approaches in promoting specific social skills of students with $\mathrm{E} / \mathrm{BD}$. In direct instruction of social skills, we must:

1. Select the target student(s).
2. Determine what type of prosocial skills are desired. Such prosocial behaviors might include: dealing with anger appropriately, accepting consequences of behavior, listening, accepting compliments, responding to failure, cooperating with peers, and so on.

3. Determine what types of inappropriate behaviors the student currently displays.

4. Determine if the student can't or won't demonstrate the prosocial skills.

5. Establish a group or groups for teaching social skills.

After assessing through observation, behavior-rating scales, and functional assessment, the teacher must determine if the student has a skill deficit. According to Bullock and Fitzimmons-Lovett (1997), if there is a skill deficit, direct instruction is essential. Teachers should examine commercially available materials to teach the skill. We stress the importance of modifying and adapting materials so that they are relevant to the students' backgrounds and so that the materials meet the needs of the students. Bullock and Fitzimmons-Lovett believe that there is no one ideal social skills curriculum. When teaching, it is important to incorporate the components of effective instruction:

1. Teach the skill by breaking it into small steps.

2. Demonstrate and model the skill.

3. Have students practice the skill using role-playing. Role-playing provides students with practice of the targeted social skills. According to Rutherford et al. (1996), role-playing provides the student with a safe environment for practicing the steps and the strategies necessary to develop target social skills. They suggest that the teacher present a variety of roleplaying situations in order to allow the student to use the same strategies in different social situations.

4. Provide feedback and reinforcement for practice.

5. Systematically provide a program for generalization of social skills. We know that students often are not able to generalize the social skills that we are teaching them to other settings. Rutherford et al. (1996) discuss the use of opportunity teaching for promoting generalization of social skills in natural settings such as hallways, cafeterias, other classrooms, and so on. The technique calls for cueing or prompting students who have missed an opportunity to use the social skill in the other environment. Students are provided with corrective feedback when they apply the social skills incorrectly and are praised for appropriate demonstration of the skills.

ASSET is a commercial program designed to develop social skills of adolescents with special needs who demonstrate 
difficulties in social functioning (Hazel, Schumaker, Sherman, \& Sheldon-Wildgen, 1981). The program, which has also been used in regular classrooms, emphasizes the following eight fundamental skills: giving positive feedback, giving negative feedback, accepting negative feedback, resisting peer pressure, being able to negotiate, solving personal problems, following directions, and conducting conversations. Each skill is then divided into components that are sequenced for instruction. ASSET employs a nine-step process to teach social skills to secondary students by using commercial materials. The nine steps are as follows:

1. Review previously learned skills and evaluate and integrate homework.

2. Explain the skill that is the focus of the current lesson.

3. Explain the reason the skill needs to be learned.

4. Provide examples of situations in which the skill can be used.

5. Examine the skills that are needed. A skills sheet that lists component skills is provided to the students.

6. Use videotapes for modeling.

7. Provide opportunities for verbal rehearsal. Students practice saying the skill components and play games and engage in activities that teach them the skills.

8. Provide the opportunity for students to role-play, performing the subskills and overall skills.

9. Provide homework so that the students can practice the subskills and skills outside of the classroom.

\section{THE TEACHABLE MOMENT}

Often when a behavioral problem occurs, the teacher will provide a consequence for the student and then will forget the incident. Unfortunately, the teacher has missed the "teachable moment"- the opportunity to take a negative situation and turn it into a learning experience. We cannot assume that the student knows the appropriate response to the situation. It is possible that the student needs to be taught. The teacher has a perfect opportunity to teach the child how to respond appropriately, so that the student does not get in trouble again. An example: Mumbling, so no one else can hear, Jimmy addresses Billy by an inappropriate name. Billy gets mad and hits Jimmy. Billy gets into trouble because no one heard Jimmy. Billy receives an appropriate consequence, but the teacher should also use this event to teach Billy what he could do if this situation occurs again. The teacher should consider that Billy may have a "short fuse" that comes from a family in which violence may be a frequent occurrence. Billy's father may have taught him that when someone irritates you, hit. Billy did what he knew how to do. More appropriate options must be explored with Billy.
Once the student is calm, the teacher can help the student assess and process the event by asking: What happened? What did you do? What can you do the next time it happens? In the example, the teacher would ask Billy, "What happened?" Billy would have immediately said: "Jimmy called me a name." (Students typically will focus on what someone else did.) The teacher would then ask: "What did you do?" Then Billy would reluctantly state that he hit Jimmy. The teacher would then ask: "What could you do the next time that Jimmy calls you a name?" Billy might first state that he could hit Jimmy again. The teacher would then ask the student if that was an appropriate response. Billy would say, "No." The teacher could then say, "What else could you have done?" Billy would respond: "I could ignore him." The teacher would reinforce the student positively and then might ask the student if there was anything else the student could do. Billy might say that he could tell the teacher. The teacher would reinforce the student again. The teacher would then leave the student with a positive word, expressing confidence that the student can handle the situation appropriately if another incident would occur. The teacher should also reinforce the student for speaking calmly.

\section{THE TEACHER AS A ROLE MODEL FOR APPROPRIATE SOCIAL SKILLS}

It is important for teachers to remember that they are role models for their students. How teachers treat students, how teachers deal with anger, frustrating situations, or a crisis sets the tone for the classroom. We firmly believe that we must treat children with respect if we wish to gain respect. When teachers reprimand students in front of others, point their fingers in students' faces, or yell at them, they send messages to students that they do not respect them. No adult wants to be treated in such a negative manner; we should remember not to treat students negatively.

\section{RECOGNIZING APPROPRIATE SOCIAL SKILLS}

We know that positive feedback for appropriate behavior is critical. As Walker et al. (1995) state: "As with the acquisition of academic skills it is important to look for spontaneous displays of expected behavior and to provide behavior-descriptive praise for them" (p. 134). Johns and Carr (1995) concur: "Teachers should never miss an opportunity to honestly accent the positive. In our opinion, at least $70 \%$ of the comments teachers give students each day should be positive" (p. 25).

An example: Aubrey has a whole repertoire of inappropriate behavior, and the bus ride to school with 14 other students is very difficult for him. One day there was a major problem with three students on the bus, which the bus driver 
came in to report. Almost immediately, all staff members assumed that Aubrey was one of the three. However, Aubrey was not involved at all. As a matter of fact, he had stayed in his seat and ignored the trouble. He even apologized to the bus driver for the trouble. When the principal learned how Aubrey had handled the situation, she went to the classroom and asked to see Aubrey privately. Aubrey immediately thought he was in trouble. However, the principal proceeded to tell him that she had heard about the trouble and was very proud of the mature way that Aubrey had handled the situation. Aubrey was very proud of himself.

\section{SPECIAL GROUP PROJECTS}

Walker et al. (1995) believe that all students in a classroom should be exposed to a core set of skills from which all of them can benefit. A group project is an appropriate method of exposing an entire class or school to these skills. Group projects might include the following:

Pom-Pom Day. The goal is to teach students how to give and receive compliments. Warm fuzzy pom-poms, which are to be worn around the neck, are given to students and staff members. The task for each participant is to give and to collect pieces of yarn from the pom-pom. To do this, participants must give a compliment to another participant.

Giving thanks during the month of November. The goal is to teach students to say "Thanks" when someone does something nice for them. Students throughout the school are given thank you cards. A bulletin board or large poster for each class is placed in a central location. Students write thank you notes to those within the school and classroom who do something nice for them. The thank you notes are placed on the bulletin board. The object is to see which class can have its bulletin board filled first.

Reflecting on the things for which we are thankful. The goal is to teach students to reflect on the positive things in their lives. Students and staff are asked to make a poster depicting 50 things they are thankful for. The posters are displayed in the hall.

Holiday gifts. The goal is for students to reflect on their strengths. Students and staff members use construction paper and ribbon to create "packages" that can be displayed in the hall. Gift tags identify the participant's package. On the package, participants describe their talents and strengths.

New Year's Resolution. The goal of this project is to set and attain a goal for the month. Each student and staff member is given a sheet of paper on which the participant writes down a goal to accomplish during the month of January. The sheets are posted for all to see. Prizes are given to participants who meets their January goals.

Start each day with a smile. The goal of this project is to stress the importance of a smile. For a month, as students enter the building, they are greeted by staff who observes if the students are smiling. When a smile is seen, a smiley face coupon is given to the student. At lunch, a drawing is held for a smiley face cookie. At the end of the month, all coupons are entered into a drawing for a giant cookie.

Teachers will find these projects most effective when the whole school or the whole classroom participates.

\section{CONFLICT RESOLUTION}

According to Johnson and Johnson (1995), violence prevention programs alone are not sufficient. They must be supplemented by programs in conflict resolution, a key component in any effective curriculum for students with emotional and behavioral disorders. Johns and Keenan (1997) believe that if we can teach students to abandon violence and resolve conflicts in other ways those students will not only have more positive relationships with peers and peace of mind, they will want to use the techniques increasingly in their everyday life.

Conflict resolution teaches negotiation skills and higher level thinking. Life is full of situations individuals must negotiate. Through conflict resolution, students learn how to negotiate. Conflict resolution is also more effective than suspensions and detentions in shaping appropriate behaviors. Rather than removing students from a situation and allowing them to escape the problem, conflict resolution teaches students to face the problem and resolve the conflict peacefully.

The process we use has been adapted from the work of Fred Schrumpf (1991):

A. Bring the two parties who have the conflict together.

B. Have the parties sit facing each other with the mediator at the head of the table.

C. The mediator opens the session, introducing himself or herself as the mediator; and each disputant introduces himself or herself. The mediator then provides the ground rules, which are:

1. The mediator is neutral and does not take sides.

2. The session is confidential; no one in the room discusses the proceedings with anyone.

3. Each party is to respect the other party by listening and by not interrupting when the other is speaking.

4. It is important for both parties to cooperate in order to resolve the dispute.

The mediator should obtain a commitment from the parties to follow the ground rules.

D. The mediator then begins the process of gathering information.

1. Each disputant is asked to tell his or her side of the story. "Will you each tell me what happened?" 
2. The mediator listens, summarizes, clarifies, repeats statements, rephrases to check accuracy, sums up the statements of the disputants.

3. The mediator then repeats the process asking for additional information. "Is there anything you want to add?"

4. The mediator then restates both sides of the situation.

5. The mediator then focuses on common interests, asking such questions as: What do you want? If you were in the other person's shoes, how would you feel? If you could ask the other person to do one thing, what would it be?

6. After gaining insight into the students' interests, state what the interests are.

7. The mediator then asks the disputants to come up with possible solutions that might satisfy both parties.

8. The mediator then asks the disputants to evaluate options and choose solutions.

9. The mediator then writes the agreement and closes by asking each participant to sign it.

\section{TEACHING SOCIAL SKILLS THROUGH SELF-MANAGEMENT STRATEGIES}

Our goal should be to teach students how to manage their own behavior. It is important to discuss some social skills strategies that students can be taught to use in solving interpersonal problems. According to Vaughn, Bos, and Schumm (1997), the goal is "to teach students to identify their problems, goals, and a wide range of alternative strategies for effectively solving their problems" (p. 85). They believe that four components are critical in problem solving: problem identification, generation of alternative solutions, identification and evaluation of the consequences of the alternative solutions, and solution implementation.

Vaughn et al. (1997) discuss two strategies that were developed by Vaughn to teach students a method to solve problems. The first strategy, known by the acronym FAST, suggests that students consider problems, identify alternatives, and evaluate the consequences. The steps of FAST are as follows:

F: Freeze and Think. Students must identify the problem and view it from their own perspective as well as from the perspective of the other student(s) involved.

A: Alternatives. Students generate alternative solutions and learn how to categorize the solutions generated.

S: Solution Evaluation. Students select several of the options and evaluate the consequences of the alternatives.
T: Try It. Students practice and implement the solution, evaluating its effectiveness. If it is not effective, the student goes back to step two (Alternatives).

SLAM, another strategy developed by Vaughn and compatible with FAST, aims to teach students to accept and respond in an appropriate manner to negative feedback from others:

S: Stop. Students stop what they are doing and take a breath when they receive negative feedback.

L: Look. When a student receives negative feedback, the student should stop all activity and look at the person who gave the negative feedback.

A: Ask. The student should ask questions to clarify the meaning of what the other person has said.

M: Make. The student makes an appropriate response to the other person.

PEACE is an effective strategy developed by Lantieri and Patti (1996) for teaching students how to handle a conflict:

P: Practice calming down. Take deep breaths and tune in to your feelings.

E: Express your point of view. Be strong without being mean.

A: Agree to work it out. Listen well. Acknowledge the other person's feelings.

C: Choose a solution that works for everyone. Brainstorm lots of possibilities first.

E: Encourage others to be nonviolent. See conflict as a problem to be solved, not a contest to be won. (p. 44)

Another strategy (taken from Anger Management for Youth: Stemming Aggression and Violence by Eggert [1994]) is known as COPING. It aims to teach students to use selftalk phrases to cope with anger:

C: Calm down: Say, "calm down" or "stop."

O: Overcome the negative; opt for control: Say, "Overcome. Easy does it. I am in control."

P: Prepare; problem-solve; plan: Say, "think, problemsolve, remember your plan."

I: Identify; invite alternatives rather than using insults: Say, "Imagine success. Don't use insults."

$\mathbf{N}$ : Name the angry feelings and negotiate: Say, "I'm angry, I need to think about negotiation."

G: Go; get on with the plan; give praise to self and others: Say, "Way to go! Good job!" (p. 114).

During the process of teaching these strategies to students, teachers will find that role-playing each step is critical because it helps students become aware of their own inappropriate behaviors. Deshler et al. (1996) give these guidelines for effective role-playing: 
a. Establish clear objectives.

b. Identify roles to be played and specify how each player should act.

c. Establish what participants should think about and observe during role-playing.

d. Remember that participation in role-playing is more effective than observation.

e. Role-playing should be at least partially scripted. (p. 398)

Deshler et al. (1996) recommend three self-monitoring activities that can be included in the process of teaching social skills to students. The first is interviewing. As a form of modeling this technique, the teacher asks students if they are aware of their own behavior, if they know why their behavior is a problem, if they have ideas as to why they engage in the behavior, if they desire to change their behavior, and what alternatives could be used to change the behavior. Interviews can be used to monitor the students' progress and help them participate in devising and then monitoring the chosen intervention process.

Keeping a journal is another self-monitoring technique. The students keep notes on their social interactions and the progress of interventions. By keeping a journal, students can reflect on their own behavior. Common options include having students make notes whenever they perform a newly learned skill, at certain times or once or twice during the day.

Keeping a record of one's own behavior is the third selfmonitoring technique. The students can use a tally sheet to keep track of the incidents involving a particular behavior. A tally sheet can be attached to the desktop or to a notebook cover.

Rosenthal-Malek (1997) stresses the importance of using metacognitive strategies to teach students social skills. She teaches children as young as 3 years of age how to interact cooperatively by using a self-interrogation strategy. Such strategies consist of a series of questions that the student employs during a problem-solving situation. For instance, to help the child to interact appropriately in a free-play situation, the student is taught six general self-interrogation questions:

1. Stop and think!

2. What (or who) do I want to play with?

3. What will happen if ?

4. How do I feel (happy, sad, angry)?

5. How does my friend feel (happy, sad, angry)?

6. What (or who) else could I play with? (p. 30)

In the area of self-management, anger management and control are essential. Walker et al. (1995) believe that it is important to teach students to recognize when they are angry and the emotional psychological arousal that accompanies anger; to identify the situations and events that seem to trigger intense anger; to recognize the unpleasant consequences that can result from intense expressions of anger; and to learn appropriate methods of expressing anger and dissatisfaction.

Goldstein and Glick (1987) have developed a very important program for adolescents. Aggression Replacement Training consists of three coordinated interventions. The first, Structured Learning, is a set of procedures designed to enhance prosocial skills levels. Modeling, role-playing, performance feedback, and transfer-training are used. The second, Anger Control Training, teaches antisocial behavior inhibition. Moral Education, the third intervention, is centered around dilemma discussion groups.

Skillstreaming, another excellent structured learning approach, was developed for early childhood students, elementary students, and adolescents. Goldstein, Sprafkin, Gershaw, and Klein (1980) define this structured learning approach for the adolescent as "a psychoeducational intervention designed specifically to enhance the prosocial, interpersonal, stress management, and planning skills of the aggressive, withdrawn, immature, and 'normal' but developmentally lagging adolescent" (p. 11).

\section{SELECTING SOCIAL SKILLS CURRICULUM}

Sugai (1995) offers this checklist to be used in determining whether a published social skills curriculum should be utilized:

1. Is a behavioral or cognitive-behavioral approach to teaching social skills emphasized?

2. Are prerequisite teaching skills for using the curriculum indicated?

3. Are the chronological ages and developmental levels of the students who would benefit from the curriculum indicated?

4. Are adaptations and accommodations for individualizing instruction provided?

5. Has the curriculum been field-tested? (p. 3)

\section{REFERENCES}

Bullock, L., \& Fitzimmons-Lovett, A. (1997). Meeting the needs of children and youth with challenging behaviors. Reaching Today's Youth: The Community Circle of Caring Journal, 1(3), 54-61.

Deshler, D., Ellis, E., \& Lenz, B. K. (1996). Teaching adolescents with learning disabilities: Strategies and methods. Denver: Love.

Eggert, L. (1994). Anger management for youth: Stemming aggression and violence. Bloomington, IN: National Educational Service.

Goldstein, A., \& Glick, B. (1987). Aggression replacement training. Champaign, IL: Research Press.

Goldstein, A., Sprafkin, R., Gershaw, N. J., \& Klein, P. (1980). Skillstreaming the adolescent. Champaign, IL: Research Press. 
Gresham, E. (1998). Social skills training: Should we raze, remodel, or rebuild? Behavioral Disorders, 24(1), 19-25.

Hazel, J. S., Schumaker, J. B., Sherman, J. A., \& Sheldon-Wildgen, J. (1981). ASSET: A social skills program for adolescents. Champaign, IL: Research Press.

Johns, B., \& Carr, V. (1995). Techniques for managing verbally and physically aggressive students. Denver: Love.

Johns, B., \& Keenan, J. (1997). Techniques for managing a safe school. Denver: Love.

Johnson, D., \& Johnson, R. (1995). Reducing school violence through conflict resolution. Alexandria, VA: Association for Supervision and Curriculum Development.

Lantieri, L., \& Patti, J. (1996). Waging peace in our schools. Reaching Today's Youth, 1(1), 43-47.

Mathur, S., \& Rutherford, R. (1996). Is social skills training effective for students with emotional or behavioral disorders? Research issues and needs. Behavioral Disorders, 22(1), 21-27.

Quinn, M. M., Kavale, K. A., Mathur, S. R., Rutherford, R. B., \& Forness, S. R. (1999). A meta-analysis of social skill interventions for students with emotional or behavioral disorders. Journal of Special Education, 7(1), 54-64.

Rosenthal-Malek, A. (1997). Stop and think: Using metacognitive strategies to teach students social skills. Teaching Exceptional Children, 29(3), 29-31.
Rutherford, R., Quinn, M., \& Mathur, S. (1996). Effective strategies for teaching appropriate behaviors to children with emotional/behavioral disorders. Reston, VA: Council for Children with Behavioral Disorders. Mini-Library Series on Emotional/Behavioral Disorders.

Schrumpf, F. (1991). Peer mediation. Champaign, IL: Research Press.

Shores, R., \& Jack, S. (1996). Special issue on research needs and issues in education for students with emotional and behavioral disorders. Behavioral Disorders, 22(1), 5-7.

Sugai, G. (1995). Selecting and designing social skills instructional materials. An unpublished handout presented at the International Conference on Behavioral Disorders Preconference Workshop, Dallas, TX, October 7, 1995.

Vaughn, S., Bos, C., \& Schumm, J. S. (1997). Teaching mainstreamed, diverse, and at-risk students in the general education classroom. Boston: Allyn and Bacon.

Walker, H., Colvin, G., \& Ramsey, E. (1995). Antisocial behavior in school: Strategies and best practices. Pacific Grove, CA: Brooks/Cole.

Warger, C., \& Rutherford, R. (1993). Co-teaching to improve social skills. Preventing School Failure, 37(4), 21-27.

\section{PERMISSIONS AND COPYRIGHT}

All rights are reserved. No part of this publication may be reproduced, photocopied, faxed, stored in a retrieval system, or transmitted in any form or by any means, electronic, mechanical, recording or otherwise, without the prior written permission of the publisher.
Back issues are available for sale. Reproduction requires permission and payment of fees. It is illegal and a violation of federal copyright law to reproduce this publication without permission. Direct all inquiries to the permissions editor. 